\title{
TJTCVS 2021; wind of change
}

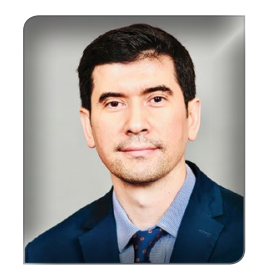

\author{
TGKDCD 202 1; değişim rüzgarı
}

\author{
Şahin Şenay \\ Department of Cardiovascular Surgery, Acıbadem Mehmet Ali Aydınlar University, School of Medicine, Istanbul, Turkey
}

This is the third and the last editorial within our term. As the Editorial Board of the Turkish Journal of Thoracic and Cardiovascular Surgery (TJTCVS), we would like to thank all of our authors and reviewers for their continuous support during last two years.

The TJTCVS is a Science Citation Index-Expanded journal that evolved with great dedication of our previous editors and recently has changed in specific aspects for the past two years. The acceptance for PubMed Central indexing was one of the milestones that increased our international visibility. The overall citations increased by $40 \%$ in 2020, compared to 2019 . The increase in citations is essential for our future impact. Meanwhile, the number of total submissions also increased by $50 \%$ and international submissions increased by $58 \%$ during the same period. I would like to congratulate each member of our editorial board, secretary office and publishing office; Bayçınar Medical Publishing, for successfully handling this major work load. We believe this increase of submissions will lead to a superior content quality and increased impact in the next couple of years.

In this context, we had a strong cooperation with the Clarivate. The first step of this cooperation was training of our reviewers. The second one was the launch of Publons 'Reviewer Connect' and 'Reviewer Recognition' systems into our journal structure. These tools are essential for high-quality reviewership and would obviously help improve the scope and the standards of our journal. I would particularly thank to our IT office; Pleksus, that integrated these tools successfully into our local editorial system.

During this term, two new article types were introduced; video articles and new ideas. Also, invited reviews and national guidelines/consensus reports were in our focus. The top downloaded article was a video article and top cited one was an invited review. This was accomplished by the clear support of our distinguished authors and the Turkish Society of Cardiovascular Surgery. Thank you for this great support. This picture has inspired us to courage our authors to give more attention on these types of articles. We believe that all these efforts would have a positive impact on the journal's recognition.

I believe that our editorial board has achieved major goals with high standards during the last 2 years, but there is and should be still way to go for improving our journal. I am sure the next editorial board will succeed doing much more to increase the journals' scope. What we only need is coming together in the guidance of science, nothing else but science.

Thank you all

Editor in Chief

Received: April 19, 2021 Accepted: April 19, 2021 Published online: April 26, 2021

Correspondence: Şahin Şenay, MD. Acıbadem Maslak Hastanesi Kalp ve Damar Cerrahisi Bölümü, 34457 Maslak, İstanbul, Turkey. Tel: +90 212 - 3044267 e-mail: sahinsenay@gmail.com 